\title{
THREE-DIMENSIONAL GEOMETRY OF THE NARWHAL (MONODON MONOCEROS) FLUKES IN RELATION TO HYDRODYNAMICS
}

\author{
JANET E. FONTANELLA \\ Department of Biology, \\ West Chester University, \\ West Chester, Pennsylvania 19383, U.S.A.
}

FRANK E. FISH

Department of Biology, West Chester University, West Chester, Pennsylvania 19383, U.S.A.

\section{NATALIA RYBCZYNSKI}

Canadian Museum of Nature, Ottawa, Ontario K1P 6P4, Canada

MARTIN T. NWEEIA

Harvard University

School of Dental Medicine

Boston, Massachusetts 02115, U.S.A., Smithsonian Institution Washington, D. C. 20227, U. S. A. 
DARLENE R. KETTEN

Biology Department

Keywords: flukes, narwhal, Monodon monoceros, hydrodynamics

Woods Hole Oceanographic Institution, Woods Hole, MA 02543 U.S.A.

Department of Otology and Laryngology, Harvard Medical School, Boston, Massachusetts 02114, U.S.A.

(2)

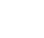

Cetaceans (whales, porpoises, and dolphins) use only their flukes for propulsion. Flukes are distally located extensions of the tail, and from a biomechanical standpoint, function as a pair of wings (Vogel 1994). Flukes function to produce thrust generated as an anteriorly directed lift force as flukes oscillate vertically (Fish 1998 a,b). Their cross-sections resemble hydrofoils. For a hydrofoil to be effective, a large lift must be produced while drag is minimized; this, in turn, increases the thrust generated (Weihs 1989; Vogel 1994).

42 sections (i.e., parasagittal) of the flukes. Cross-section profiles taken along the horizontal axis 43 exhibit what is a typical streamlined hydrofoil profile with a rounded leading edge and a long, 44 tapered trailing edge. This shape is critical for the generation of lift for thrust, while minimizing 45 induced drag (i.e., drag due to lift production; Lighthill 1970; Vogel 1994). The flukes are 46 symmetrical about the chord (Lang 1966; Bose et al. 1990). The cross-sectional profile of the 
47 flukes is similar to symmetrical engineered foils (Fish 1998b). The similarity to engineered foils

48 would imply that cetacean flukes would be capable of effectively generating large lift with low

49 drag at higher angles of attack.

50 The typical planform shape of cetacean flukes is characterized as a tapered wing with

51 sweepback (i.e., rearward inclination of the leading edge). Such a wing shape can achieve

52 improved efficiency by reducing induced drag by $8.8 \%$ compared to a wing with an elliptical

53 planform (van Dam 1987). Minimal induced drag occurs in swept wings with a triangular

54 planform approximating the design of most cetacean flukes (Chopra and Kambe 1977; Fish

55 1998b). Aspect ratio $(A R)$ measures the relationship between the span and planform area of a

56 hydrofoil and is related to the effectiveness of the hydrofoil's design. A low $A R$ is characterized

57 as a short, broad wing, whereas a high $A R$ wing is long and narrow. A combination of low sweep

58 with high $A R$ allows for high-efficiency rapid swimming, whereas high sweep may compensate

59 for the reduced lift production of low-AR flukes (Azuma 1983; Liu and Bose 1993). Highly

60 swept, low-AR wings produce maximum lift when operating at high angles of attack, when low-

61 sweep, high-AR designs would fail (Hurt 1965). This feature aids in the maintenance of high

62 efficiency at slow, sustained speeds (Magnuson 1978), as observed in Monodon monoceros, the

63 narwhal. In general, narwhals are regarded as very slow swimmers that seldom exceed speeds of

$641.7 \mathrm{~m} \mathrm{~s}^{-1}$ (Minasian et al. 1984). Although increasing efficiency, the high sweep angle will

65 reduce thrust. Maintenance of thrust would be facilitated by a higher $A R$ hydrofoil planform.

66 The external morphology of flukes is generally considered constant among the Cetacea.

67 An acute departure from the typical fluke shape is found in the narwhal. Narwhals are regionally

68 circumscribed cetaceans that inhabit the Arctic Ocean Atlantic sector (Heide-Jørgensen 2009).

69 They are widely distributed in the ice-packed stretches of waters bordering Greenland and the 
70 Canadian High Arctic (Laidre et al. 2003). The flukes of mature male narwhals have a slightly

71 concave leading edge without sweepback (Fig. 1; Hay and Mansfield 1989). A female narwhal

72 generally has a fluke very similar in shape to that of a dolphin, which is swept back (Fig. 1).

73 Whether or not the differing fluke morphology is an evolved adaptation that coincides with the

74 long, tapering tusk present on most males is unknown (Fish et al. 2007).

75 In this study, we compared the fluke geometries of male and female narwhals, which may

76 be associated with hydrodynamic effects. CT (Computerized tomography) scanning was used to

77 obtain data for analyses of the three-dimensional geometry of the flukes.

78 The flukes from four narwhals (two males and two females) were obtained from

79 aboriginal hunters in the vicinity of Broughton Island, Canada. The body lengths of the animals

80 ranged from 2.98-3.60 m (Table 1). Both males had erupted, upper left tusks. Standard body

81 measurements were made including the span of the fluke (i.e., linear distance between fluke

82 tips).

The flukes were frozen and shipped to the Canadian Museum of Nature in Ottawa,

84 Canada. The frozen flukes were later transported to the Woods Hole Oceanographic Institution

85 CT imaging facility for scanning. The flukes were placed flat, dorsal side up, on the scanner

86 table, stabilized with plastic wedges and Styrofoam sheets, and scanned tip to tip with span-wise

87 parasagittal cross-sections.

88 CT scans were obtained on a Siemens Volume Zoom CT scanner. Spiral protocols for

89 data acquisition with 0.5- to $1.0-\mathrm{mm}$ detector collimation at $1 \mathrm{~mm} / \mathrm{sec}$ table feeds were used. All

90 images were reconstructed in both soft tissue and ultra-high resolution kernels with extended

91 attenuation scales to improve discrimination of high density elements. Images were obtained in

92 DICOM formats, and for some data, were reconstructed at $100-\mu$ slice intervals that provide 100 
$93 \mu$ isotropic voxels needed for finer grain structural analyses. With these parameters, the

94 maximum in-plane resolution was $0.35 \mathrm{~mm}$ at $2 \%$ of the modulation transfer function. Prior

95 studies suggest $25 \mu$ in-plane pixel resolutions are possible, but a conservative nominal

96 resolution is $50 \mu$.

97 Because true data base magnifications cannot be obtained from enlargements of

98 processed image files, raw attenuation data were archived onto magneto-optical disks for all

99 scans in order to allow additional post-scan processing as needed. Image files were archived in

100 DICOM format and 512 matrices on CD. The DICOM images of fluke cross-sections were

101 analyzed using OsiriX (OsiriX Foundation, Geneva, Switzerland, version 2.7.5). A total of 2,715

102 fluke cross-sections were examined for all four specimens; this figure excludes the tailstock

103 cross-sections, for which leading and trailing edges of the flukes were not visible.

104 Measurements of the fluke planforms (Fig. 2) included the span (FS; distance from fluke

105 tip to fluke tip), fluke blade span (BS, distance from root fluke chord; $R C$, to tip of fluke),

106 planform area ( $F_{a}$; total planar area of flukes on the dorsal surface), and sweepback $(\Lambda) . R C$ is

107 the chord at the intersection of the fluke blade and the tailstock. The sweepback was measured as

108 the angle between a line extending from $25 \%$ of the fluke chord extending from the cranial end

109 of $R C$ and to the maximum lateral extension of the fluke tip and a line perpendicular to $R C$ (Hurt

110 1965, Fish 1998a, b). The aspect ratio (AR) of each fluke was calculated as $F S^{2} / F_{a}$.

111 Measurements of fluke sections for each CT slice (Fig. 2) were made for the chord length

112 (C), maximum thickness (T), shoulder (S), and leading edge radius (LER) (Fish et al. 2006,

113 2007). $C$ was measured as the linear distance from the leading to trailing edge of the fluke. $T$ was

114 the maximum vertical distance between the upper and lower side of the fluke perpendicular to

115 the chord line. $S$ was measured as the distance from the leading edge to the maximum thickness 
116 line. For comparison of narwhals of different sizes, $C, T$, and $S$ measurements were presented as

117 a percentage of $B S$, starting at $0 \%$ at $R C$ to $100 \%$ at the fluke tip. Leading edge radius (LER) was

118 the radius of the curvature of the leading edge as determined from the radius of a circle that

119 connects tangential points of the leading edge and the upper and lower surfaces of the cross-

120 section (Hurt 1965). A circle template was used on images taken at $50 \%$ of the $B S$ on the two

121 flukes for each individual narwhal to determine radius of the leading edge. LER was presented as

122 a proportion of $C$ (Fish et al. 2007).

123 The thickness ratio $(T R=T / C)$ and shoulder position $(S P=S / C)$ of each cross section

124 were used as indicators of flow structure and the hydrodynamic performance relating to the 125 generation of lift and drag for foils (von Mises 1945; Hoerner 1965).

126 Microsoft Excel 2004 and KaleidaGraph (Synergy Software, version 4.03) were used to 127 statistically and graphically analyze the data collected. Because of differences in fluke sizes of 128 the individual narwhals, comparisons were made using means ( \pm one standard deviation). The

129 linear measurements from each CT slice $(C, T, S)$ were averaged for the corresponding slice for

130 each fluke blade for an individual animal. The mean values of each measurement and

131 morphological parameter were calculated for each sex. The small sample size precluded

132 statistical analysis beyond descriptive statistics.

133 The FS and $F_{a}$ were both greater for the male narwhals, due to their larger size. The

134 calculated values for aspect ratio did not show significant differences for male and female

135 narwhals. The main difference was the difference in $\Lambda$ between the sexes (Table 1; Fig. 1).

136 Females had a mean sweepback angle of 31.4 \pm 3.3 degrees and males had mean sweepback

137 angles of $20.5 \pm 5.2$ degrees. 
It was noted that male N0004 was slightly immature, judging by its overall smaller body

139

140

141

142

143 leading edge and a tapering, trailing edge; fluke sections were also symmetrical about the chord

144 (Fig. 2). Both right and left fluke blades were apparently symmetrical. From the root of the fluke, size and tusk and the fluke morphology was slightly swept back. Measurements of the $S$ for female N0001 were lower than expected at approximately 15\% of span (Figs. 3, 5) because of depressions on the ventral side of the cross-sections.

For both sexes, the fluke cross-sections were highly streamlined, having a rounded

$145 C, T$, and $S$ showed an approximately linear decrease to about $95 \%$ of span in which these

146 measurements decreased more rapidly toward the tip (Fig. 3). Differences between male and

147 female narwhals for $C, T$, and $S$ were only observed near the fluke root. Interestingly, there was

148 no discernable difference in sectional values for $C$ between males and females despite the

149 difference in $\Lambda$ (Fig. 3).

150 TR decreased proximally toward the tailstock (Fig. 4). The maximum values of TR

151 occurred at the fluke tip. Over the fluke span, males had a mean $T R$ of $0.23 \pm 0.02$, whereas the

152 females had a mean TR of $0.24 \pm 0.02$. Differences in $T R$ between male and female narwhals

153 were apparent from $20 \%$ to $90 \%$ of $B S$. Within this range, $T R$ for females was $5 \%$ greater than

154 for the males.

155 SP had a U-shaped distribution along the fluke blade span with the highest values at the 156 tip and root of the flukes and lowest at approximately midspan (Fig. 5). Between 20\% and 65\% 157 of span, males and females had means for $S P$ of $0.28 \pm 0.00$ and $0.30 \pm 0.01$, respectively. Over 158 this range of span the females averaged a $10 \%$ greater SP than males.

159 No apparent difference of $L E R$ was found between males and females. Mean $L E R$ values 160 were $0.05 \pm 0.01$ and $0.05 \pm 0.00$ for males and females, respectively. 
The general morphology of cetacean flukes influences the requirements of energy for

162 swimming. A highly streamlined fluke is characterized by the symmetrical nature of the cross-

163 sections in the sagittal plane. A rounded leading edge and a tapering, trailing edge are

164 characteristics shown in the cross-sections that are fundamental in the generation of lift, while 165 also reducing drag (Webb 1975, Vogel 1994).

166 The parameters TR and SP influence the pressure distribution of flow over the surface of

167 the flukes. A favorable gradient has pressure decreasing in the downstream direction, which aids

168 in flow over the fluke surface. An unfavorable gradient has pressure increasing in the

169 downstream direction. This ultimately delays the flow over the fluke's surface. The favorable

170 and unfavorable pressure gradients are located upstream and downstream of $S P$, respectively

171 (Fish 2007). An increase in drag results from an unfavorable pressure gradient, because flow will 172 tend to separate from the fluke surface (Webb 1975; Vogel 1994). Thrust increases with lift until

173 a critical point when the fluke stalls due to the separation of flow from the surface. Thus, the

174 displacement of the SP further downstream on the fluke section impedes the separation of flow

175 by extending the favorable pressure gradient. However, downstream displacement of SP will

176 foster separation, particularly when the section is canted at an angle to the flow. Mean $S P$ values

177 ranged from 0.29 to 0.38 for females and male values ranged from 0.27 to 0.36 . Female narwhals

178 had a higher $S P$ than male narwhals (Fig. 5), indicating that $S P$ was placed further downstream 179 on the fluke section.

180 Male narwhals had lower $T R$ values when compared to female narwhals. Average TR

181 values for male narwhals ranged from 0.195 to 0.285 , while female narwhals ranged from 0.207

182 to 0.442 . Streamlined foil sections have lower drags with low TR values than high TR foils

183 (Abbott and von Doenhoff 1959). Low TR foils have a small pressure gradient magnitude, which 
184 reduces drag (Fish 2007). Conversely, as the $T R$ values increase, as observed in female narwhals,

185 lift is enhanced and stall is delayed. This hydrodynamic performance would be possible because

186 the shape of the cross-section would allow the flow of water to move smoothly over the fluke

187 surface. Similarly, a high SP value leads to delayed stall. Consequently, it would appear that the

188 flukes of male narwhals have a hydrodynamic advantage in reducing drag; however, the cross-

189 sectional design of the flukes of female narwhals would tend to increase lift and delay stall.

190 Other limiting factors of induced drag include the sweep of a fluke (Fish 1998b). Female

191 narwhals have a greater sweepback in fluke planform compared to males. Sweepback of a wing

192 or hydrofoil can reduce the induced drag (i.e., drag due to lift) by as much as $8.8 \%$ compared to a

193 wing without sweepback (van Dam 1987). Swept back wings produce maximum lift generation

194 at high angles of attack (Fish 1998b). This would be advantageous particularly at low swimming

195 speeds when the angle of attack of the flukes is high (Fish 1993). However, low sweep angles

196 allow for high-efficiency, rapid swimming (Azuma 1983). Based on this information, it is

197 deduced that females would have increased lift but at low swimming speeds, whereas males

198 would have high efficiency at higher swimming speeds.

199 The hydrodynamic effects produced from differences in the geometries of the flukes,

200 which were stated above, are largely associated with steady flow conditions. The flukes of

201 cetaceans are oscillated incurring the dominance of unsteady flow conditions (Webb 1975; Fish

202 1993, 1998a). Unsteady effects can incur lower lift than for steady motion (Lighthill 1970).

203 Further analysis of narwhal fluke geometry would require examination of unsteady effects,

204 although results based on steady flow conditions can provide an indication of differences in

205 hydrodynamic performance. 
The differences in fluke design between the sexes of narwhals could have hydrodynamic

207

208

209

210

211

212

213

214

215

216

217

218

219

220

221

222

223

224

225

226

227

228

consequences associated with swimming performance. No differences in swimming speeds

between male and female narwhals have been reported, when transiting between locations as

during migrations (Dietz et al. 1995, Dietz et al. 2001, Heide-Jørgensen et al. 2002, 2003).

However, Laidre et al. (2003) found that female narwhals made more dives to deeper depths than

males. Deeper destination depths were related to increased swimming speed (Laidre et al. 2003), indicating that at least during foraging dives, females could be swimming faster than males. The design of the flukes of females, thus, may be associated with the need to transit to greater depths at fast speed. For males, the increased lift and concomitant thrust production from the low sweepback fluke design may aid in compensating for the increased drag that might accompany the possession of the elongate tusk. Swimming performance by narwhals (i.e., overcoming drag, swimming speed) is associated with the hydrodynamically complex and conflicting relationships of lift and thrust production, reduction in drag, delay in stall, and efficiency, which are dependent on the fluke geometry and kinematics.

\section{ACKNOWLEDGEMENTS}

We are indebted to Julie Arruda and Scott Cramer of Woods Hole Oceanographic Institution (WHOI) for assistance with transfers and CT scanning of the narwhal flukes and for assistance from James G. Mead and Charles W. Potter of the Marine Mammal Program of the Natural History Museum of the Smithsonian Institution, and Lisa-Marie Leclerc and Jaypootie Kooneeliusie. Sanja Hinic-Frlog assisted NR with transportation of the flukes from the Canadian Museum of Nature (CMN) to WHOI. Kamal Khidas and Peter Frank (CMN) provided much help with the paper work and accessioning. The hunters’ and trappers’ organization of 
229 Qikiqtarjuaq are gratefully acknowledged. We are extremely grateful to Kristin Laidre for

230 providing information on narwhals, which aided in the analysis of our data. The transport of all

231 materials was in accordance with CITES permits. This work was funded in part by grants from

232 the National Science Foundation (IOS - 0640185) to FEF, by CMN funding to NR, by the Office

233 of Naval Research to DRK, and by Harvard University to MTN.

\section{LITERATURE CITED}

Abbott, I. H., and A.E. von Doenhoff. 1959. Theory of Wing Sections. Dover, NY.

237 Azuma, A. 1983. Biomechanical aspects of animal flying and swimming. Pages 35-53 in: H.

Bose, N., J. Lien, and J. Ahia. 1990. Measurements of the bodies and flukes of several cetacean Matsui and K. Kobayashi, eds. Biomechanics VIII-A: International Series on Biomechanics, Volume 4A. Human Kinetics Publishers, Champaign, IL. species. Proceedings of the Royal Society of London B 242: 163-173.

Chopra, M.G. and T. Kambe. 1977. Hydrodynamics of lunate-tail swimming propulsion. Part 2. Journal of Fluid Mechanics 79: 49-69.

Dietz, R., and M.P. Heide-Jørgensen, 1995. Movements and swimming speed of narwhals (Monodon monoceros) instrumented with satellite transmitters in Melville Bay, Northwest Greenland. Canadian Journal of Zoology 73: 2106-2119.

Dietz, R., M.P. Heide-Jørgensen, P. Richard, and M. Acquarone. 2001. Summer and fall movements of Narwhals (Monodon monoceros) from Northeastern Baffin Island towards Northern Davis Strait. Arctic 54: 246-263.

Fish, F.E. 1993. Power output and propulsive efficiency of swimming bottlenose dolphins (Tursiops truncatus). Journal of Experimental Biology 185: 179-193. 
252 Fish, F.E. 1998a. Comparative kinematics and hydrodynamics of odontocete cetaceans:

253

254

255

256

257

258

259

260

261

262

263

264

265

266

267

268

269

270

271

272

273

274 morphological and ecological correlates with swimming performance. Journal of Experimental Biology 201: 2867-2877.

Fish, F.E. 1998b. Biomechanical perspective on the origin of cetacean flukes. Pages 303-324 in: J. Thewissen, ed. The Emergence of Whales: Evolutionary Patterns in the Origin of Cetacea. Plenum Press: New York.

Fish, F. E., M.K. Nusbaum, J.T. Beneski, and D.R. Ketten. 2006. Passive cambering and flexible propulsors: cetacean flukes. Bioinspiration and Biomimetics 1: S42-S48.

Fish, F.E., J.T. Beneski, and D.R. Ketten. 2007. Examination of the three-dimensional geometry of cetacean flukes using computed tomography scans: hydrodynamic implications. The Anatomical Record 290: 614-623.

Hay, K., and A. Mansfield. 1989. Narwhal Monodon monoceros Linnaeus, 1758. Pages 145-176 in: S.H. Ridgway, and R. Harrison, eds. Handbook of Marine Mammals. Vol. 4. Academic Press: San Diego, CA.

Heide-Jørgensen, M.P. 2009. Narwhal, Monodon monoceros. Pages 754-758 in: W.F. Perrin, J.G.M. Thewissen, and B. Würsig, eds. Encyclopedia of Marine Mammals. Elsevier, San Diego, CA.

Heide-Jørgensen, M. P., R. Dietz, K. L. Laidre, and P. Richard. 2002. Autumn movements, home ranges, and winter density of narwhals (Monodon monoceros) tagged in Tremblay Sound, Baffin Island. Polar Biology 25: 331-341.

Heide-Jørgensen, M. P., R. Dietz, K. L. Laidre, P. Richard, J. Orr, and H. C. Schmidt. 2003. The migratory behaviour of narwhals (Monodon monoceros). Canadian Journal of Zoology 81: 1298-1305. 
275 Hoerner, S. 1965. Fluid-dynamic drag. Published by author: Brick Town, NJ: Hoerner.

276 Hurt, H., Jr. 1965. Aerodynamics for naval aviators. US Navy, NAV-WEPS 00-80T-80.

277 Department of the Navy: Washington, DC.

278 Laidre, K.L., M.P. Heide-Jørgensen, R. Dietz, R.C. Hobbs, and O.A. Jørgensen. 2003. Deep-

279 diving by narwhals Monodon monoceros: differences in foraging behavior between

$280 \quad$ wintering areas? Marine Ecology Progress Series 261: 269-281.

281 Lang, T. 1966. Hydrodynamic analysis of dolphin fin profiles. Nature 209: 1110-1111.

282 Lighthill, J. 1970. Aquatic animal propulsion of high hydromechanical efficiency. Journal of $283 \quad$ Fluid Mechanics 44 : 265-301.

284 Liu, P. and N. Bose. 1993. Propulsive performance of three naturally occurring oscillating 285 propeller planforms. Ocean Engineering 20: 57-75.

286 Magnuson, J.J. 1978. Locomotion by scombrid fishes: hydrodynamics, morphology and 287 behaviour. Pages 239-313 in: W.S. Hoar and D.J. Randall, eds. Fish Physiology, vol. 7. 288 Academic Press, London, UK.

289 Minasian, S.M., K.C. Balcomb, and L. Foster. 1984. The World’s Whales. Smithsonian Books, 290 Washington, DC.

291 van Dam, C.P. 1987. Efficiency characteristics of crescent-shaped wings and caudal fins. Nature $292 \quad 325: 435-437$.

293 Vogel, S. 1994. Life in Moving Fluids. Princeton University Press, Princeton, NJ.

294 von Mises, R. 1945. Theory of Flight. New York: Dover Publishers.

295 Webb, P. 1975. Hydrodynamics and energetics of fish propulsion. Bulletin of the Fisheries 296 Research Board of Canada 190: 1-158. 
297 Weihs, D. 1989. Design features and mechanics of axial locomotion in fish. American Zoologist 298 29: $151-160$.

299 

Table 1. Morphometrics of fluke planforms.

301

\begin{tabular}{|c|c|c|c|c|c|c|c|}
\hline SPECIMEN & SEX & $\begin{array}{c}\text { BOdY } \\
\text { LENGTH (m) }\end{array}$ & $\begin{array}{c}\text { FLUKE } \\
\text { SPAN (m) }\end{array}$ & $\begin{array}{c}\text { PLANFORM } \\
\text { AREA }\left(\mathrm{m}^{2}\right)\end{array}$ & $\begin{array}{c}\text { ASPECT } \\
\text { RATIO }\end{array}$ & $\begin{array}{c}\text { SWEEPBAK } \\
\text { ANGLE (deg) }\end{array}$ & $\begin{array}{c}\text { TUSK } \\
\text { LENGTH (m) }\end{array}$ \\
\hline N0001 & F & 3.09 & 0.71 & 0.13 & 3.88 & 33.7 & N.A. \\
\hline N0002 & F & 2.98 & 0.70 & 0.13 & 3.63 & 29.0 & N.A. \\
\hline N0003 & M & 3.60 & 0.87 & 0.19 & 3.90 & 16.8 & 1.00 \\
\hline N0004 & $\mathrm{M}$ & 3.57 & 0.85 & 0.19 & 3.86 & 24.2 & 0.44 \\
\hline
\end{tabular}

302

303

304 
306 Figure Legends

307

308 Figure 1. CT topograms illustrating the differences between female (N0001, N0002) and male 309 (N0003, N0004) fluke planforms.

311 Figure 2. Planform and sectional fluke dimensions. The upper figure shows a fluke planform.

312 The vertical solid lines show the root chords $(R C)$ and the chord $(C)$ at $50 \%$ of the blade span.

313 The blade span extends horizontally from $R C$ to the fluke tip and the span is the horizontal

314 distance between fluke tips. The sweep angle $(\Lambda)$ is the angle subtended from a line at the $25 \%$

315 of $R C$ and the horizontal dashed line. The lower figure shows a CT image of a fluke section. The

316 horizontal line $(C)$ illustrates the chord at 50\% of blade span, the dashed vertical line is the

317 maximum thickness $(T)$, and the distance from the leading edge to the maximum thickness is the

318 shoulder $(S)$. The line within the circle indicates the leading edge radius $(L E R)$, which is

319 determined from the radius of the white circle that connects tangent points of the leading edge 320 with the upper and lower surfaces of the section.

322 Figure 3. Linear measurements of male and female flukes of the chord ( $C$; solid circles),

323 maximum thickness ( $T$; open squares) and shoulder ( $S$; open triangles) as a percentage of the

324 fluke blade span, where $0 \%$ is at the root chord and $100 \%$ is at the fluke tip.

326 Figure 4. Thickness ratio (TR) as a function of fluke blade span for male (open circles) and 327 female (solid circles) narwhals. 
329 Figure 5. Shoulder position (SP) of male (open circles) and female (solid circles) narwhals as a 330 function of fluke blade span. 
333

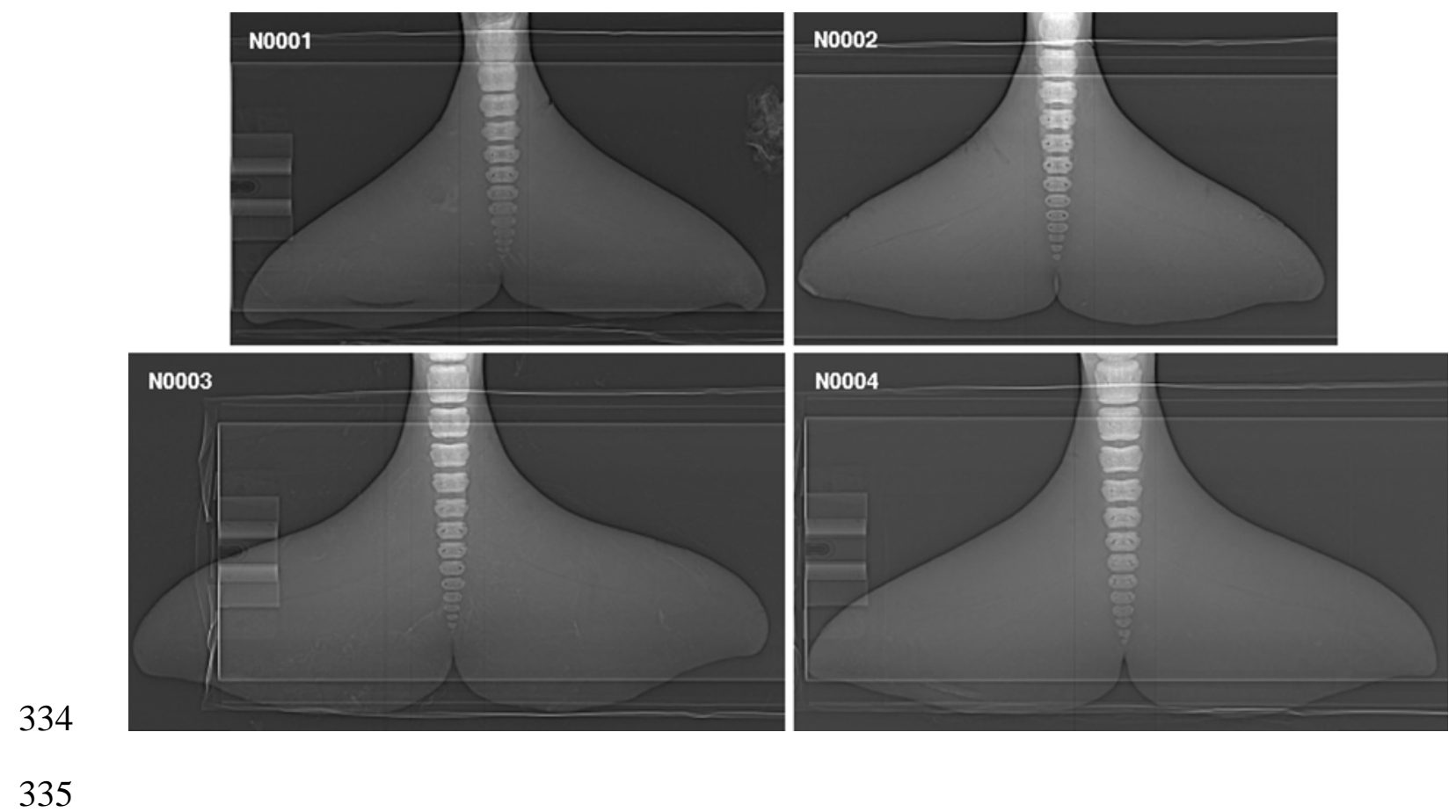

336 Figure 1. 

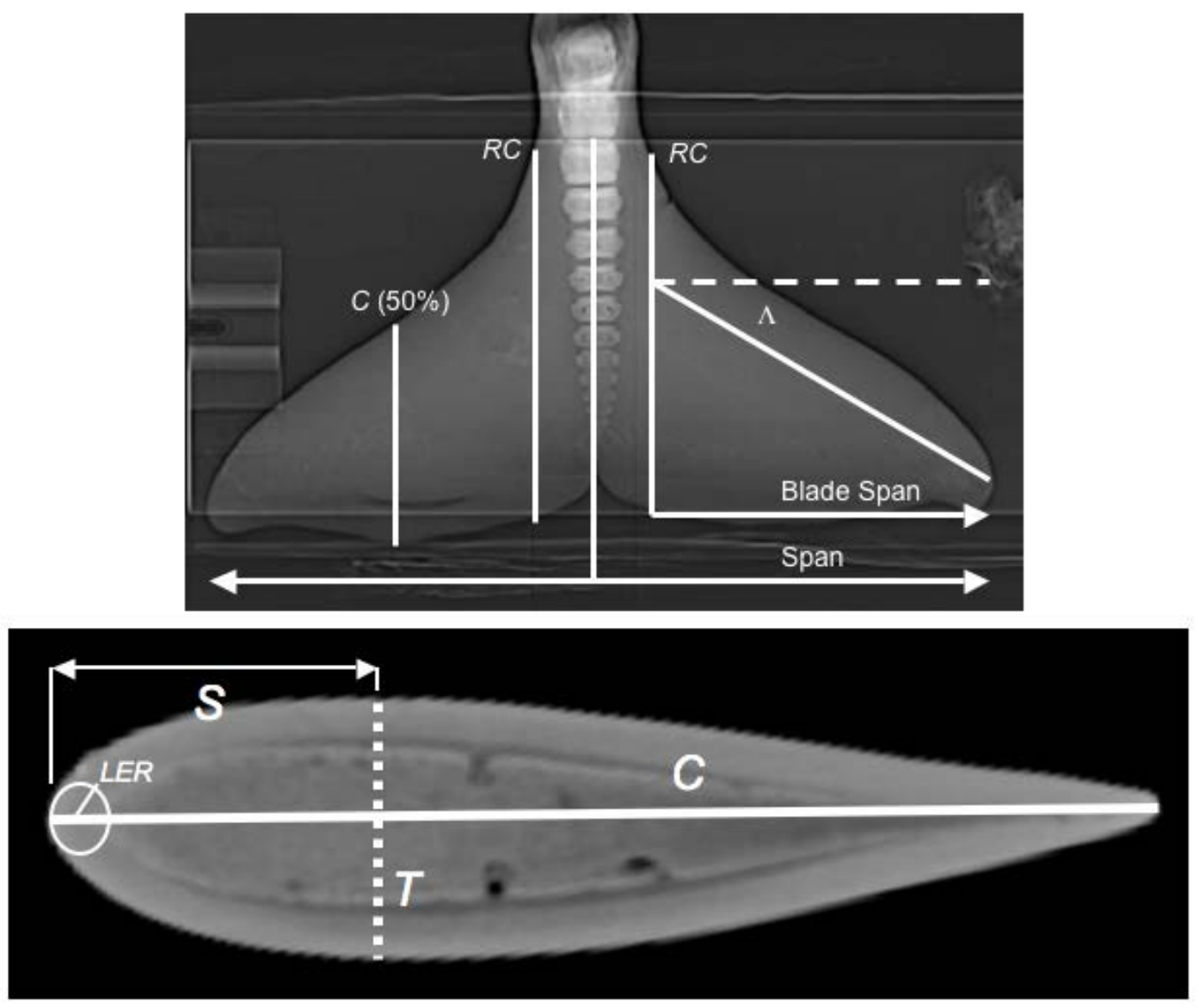

338 Figure 2. 

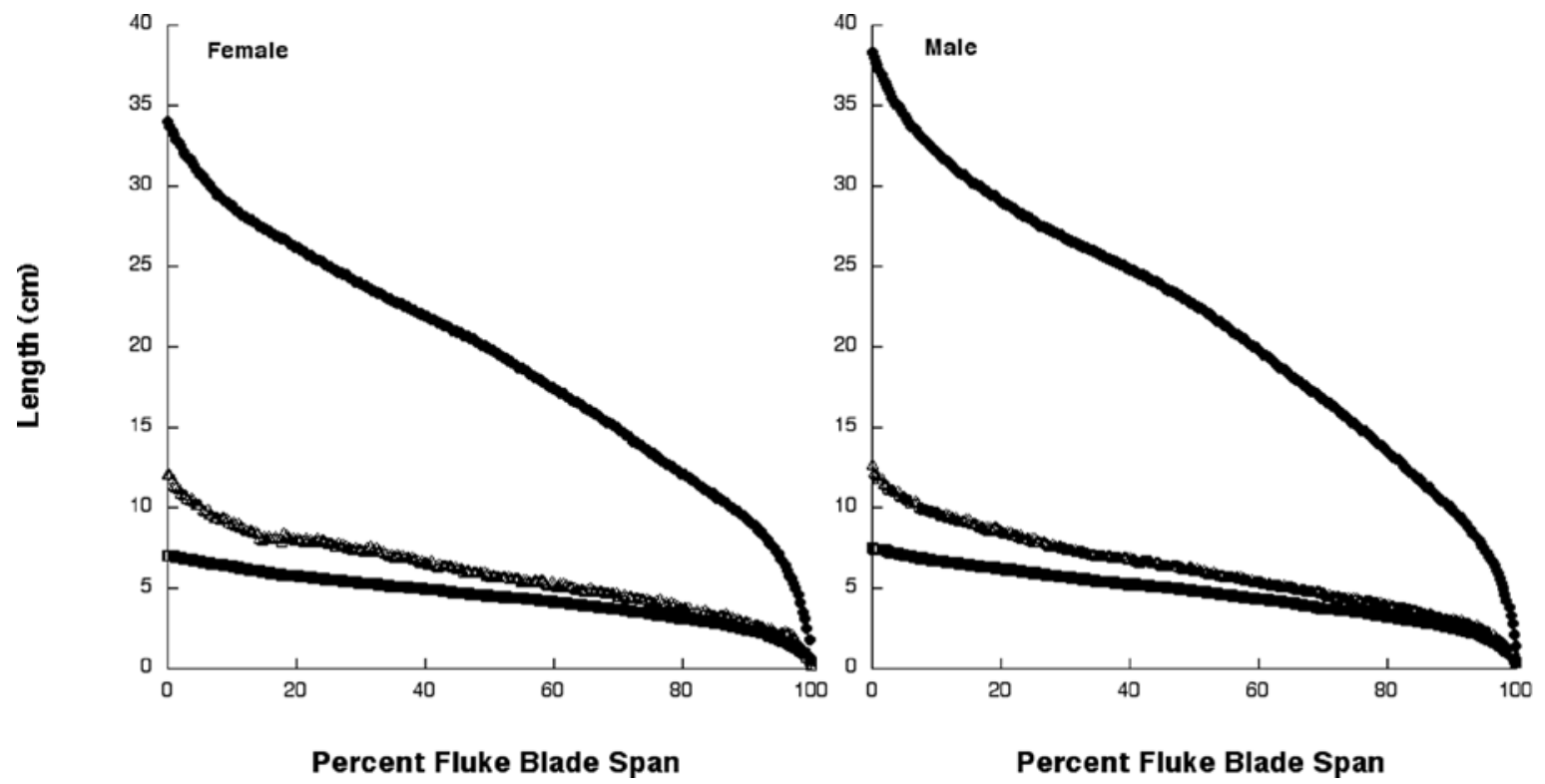

342 Figure 3. 


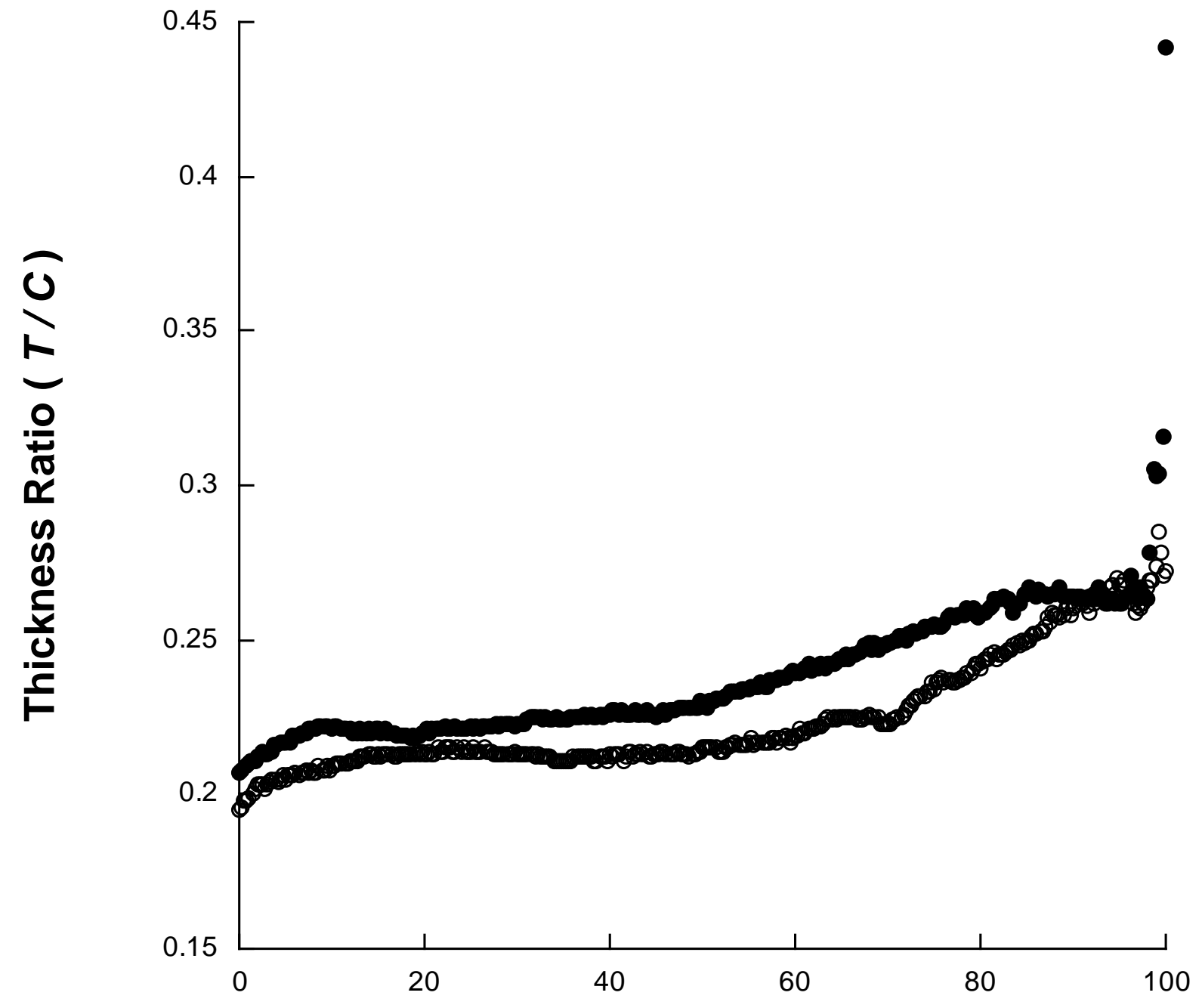




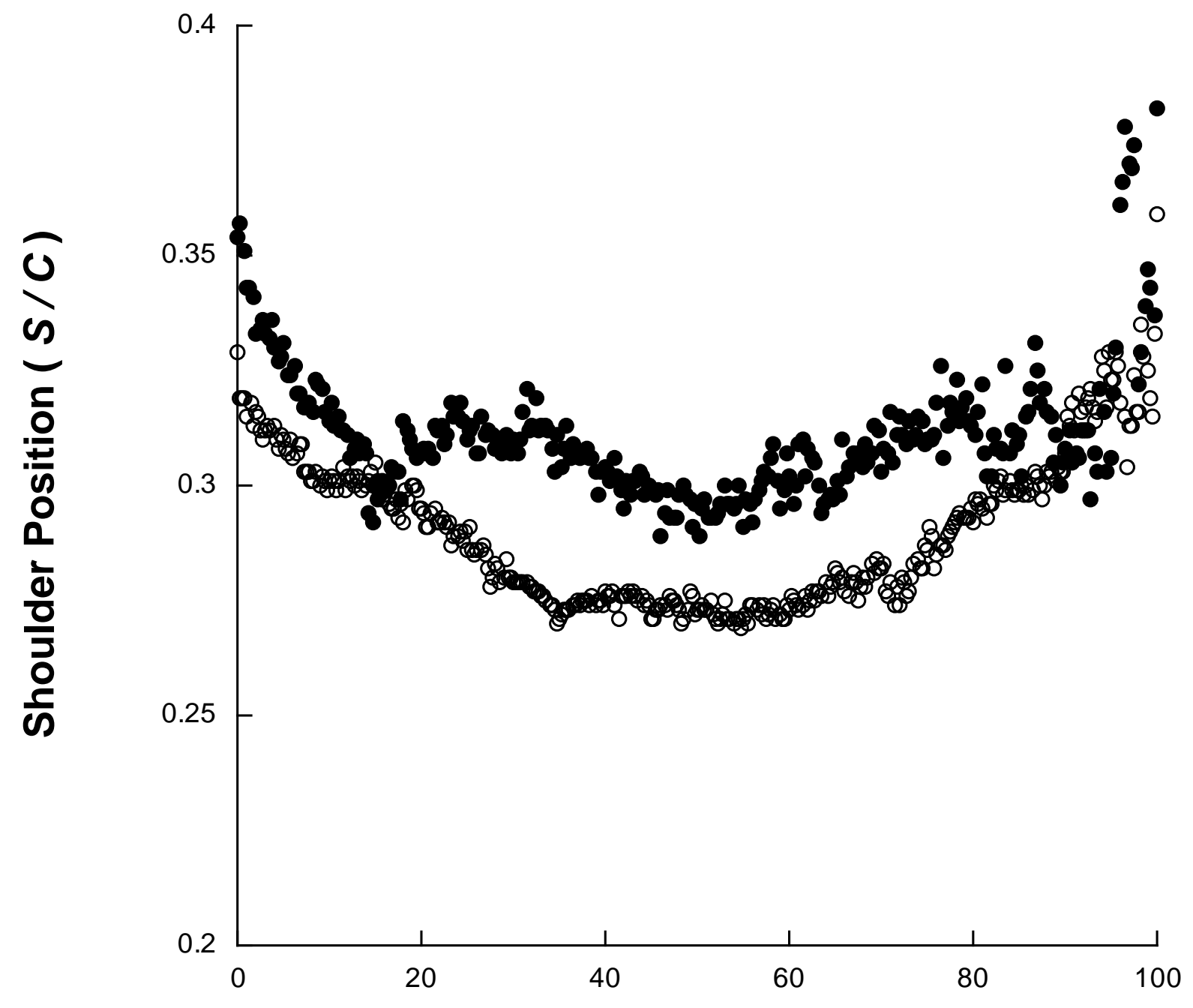

348 Figure 5 